\title{
The Influence Mechanism of Loneliness to Learning and Its Coping Strategies in Chinese College Students
}

\author{
Dong Yang and Usaporn Swekwi \\ Suryadhep Teachers College, Rangsit University, Pathumthani, Thailand \\ http://orcid.org/0000-0002-6382-0706 \\ http://orcid.org/0000-0002-2634-5344
}

\begin{abstract}
Chinese college students frequently experience loneliness during remote learning, resulting in impaired academic performance. The relationships among loneliness, mental health, and academic performance were explored for these students. Mixed method research was conducted using both investigation and interview methods. In the online survey, 437 college students were recruited from three universities in Wuhan, China. The sampling began on April 7, 2021, and ended on April 11, 2021. The reliability and validity of the scales of loneliness, mental health, and academic performance were verified by a confirmatory factor analysis model, and a higher-order model confirmed the mediating mechanism. The mediating mechanism revealed that mental health and the influence of loneliness negatively impacted academic performance. Based on this mechanism, methods for coping with loneliness were explored by interviewing 12 Chinese college students online between April 20 and April 28, 2021. Further interview data coding and classification were conducted. The interview results revealed that self-comfort and seeking assistance from others were the primary methods used by the students to alleviate loneliness. Accordingly, it is found that loneliness during independent learning significantly affects mental health, causing a decline in academic achievement among Chinese college students. Loneliness, the primary cause of the complete mediating effect of loneliness, mental health, and academic performance can be alleviated in two ways; self-comfort and asking help from others.
\end{abstract}

Keywords: loneliness; mental health; academic performance; influence mechanism; coping strategies

\section{Introduction}

The coronavirus (COVID-19) pandemic has resulted in substantial changes in students' lives (Aristovnik et al., 2020; WHO, 2020), such as the increase in 
online teaching in higher education (Mahmood, 2021). Online teaching has been the best method in preventing COVID-19 transmission among students (Mishra et al., 2020; Mahmood, 2021). Therefore, the pandemic resulted in large-scale, long-term online teaching for Chinese college students in some areas, such as at universities in Wuhan city (Wang et al., 2020). Independent learning is an effective way to cope with prolonged online teaching for Chinese college students (Zhang et al., 2020). Nevertheless, Chinese college students did not adapt to online learning by improving their independent learning capabilities (Yu et al., 2020).

Independent learning is an autonomous and prolonged learning method of adult learners, and involves studying alone without learning assistance (Leathwood, 2006). However, loneliness during independent learning can inhibit independent learning behavior (Kaufmann \& Vallade, 2020; Marsh, 1997). Feelings of loneliness occur due to a lack of social relationships, which in turn causes negative emotional stresses (Benoit \& Ditommaso, 2020; Gerino et al., 2017) and impedes learning performance (Kaufmann \& Vallade, 2020; Marsh, 1997). Stress regulation theory suggests that relationships with family and friends can reduce the effects of stress on learning outcomes (Lakey \& Orehek, 2011). Research on loneliness and learning has demonstrated that loneliness negatively affects academic performance (Hüseyin \& Barut, 2020; Mo, 2019; Yang \& Swekwi, 2021). This effect may be due to the lack of social relationships for lonely individuals (Lakey \& Orehek, 2011; Margalit, 1991), and therefore, loneliness may inhibit independent learning (Leathwood, 2006; Marsh, 1997; Stoliker \& Lafreniere, 2015), cause negative emotional stress, and affect academic achievement (Hüseyin \& Barut, 2020; Mo, 2019; Yang \& Swekwi, 2021).

However, studies of negative influencing factors, mental health, and outcomes revealed that the relationship between these was not direct, but instead mediated by mental health (Gerino et al., 2017; Miranda et al., 2013). Psychological capital theory suggests that mental health is an outcome influenced by psychological capital; negative feelings can affect an individual's psychological state and affect performance (Cavus \& Gokcen, 2015; Luthans et al., 2004). Therefore, feelings of loneliness manifesting as emotional stress may first affect mental health and then affect learning outcomes. Accordingly, the mediating mechanism of loneliness, mental health, and academic performance for independent learners was explored in this research. Whereafter, when loneliness during independent learning was confirmed as a factor that negatively affects mental health which in turn impacts academic performance, this study proposes a question to explore: How can college students cope with feelings of loneliness arising from independent learning?.

\section{Literature Review}

Loneliness, a subjective emotional stressful experience, occurs from a deficiency of social communication and feedback, and is defined as a feeling of dissatisfaction with one's interpersonal relationships (Diehl et al., 2018; Yang \& Swekwi, 2021). During independent study, feelings of loneliness can cause negative effects by causing social emotional stress (Gerino et al., 2017; Kaufmann 
\& Vallade, 2020; Leathwood, 2006; Marssh, 1997). The social psychology theory of loneliness suggests that loneliness may be caused by an individual undertaking an activity alone with the absence of adequate socializing time (Peplau \& Perlman, 1979; Stoliker \& Lafreniere, 2015). Independent learning has the characteristic of working alone without social support (Kaufmann \& Vallade, 2020; Leathwood, 2006; Marsh, 1997). Stress-regulation theory suggests that social relationships with family and friends act as a buffer for stress by assisting in problem-solving (Lakey \& Orehek, 2011). As independent learners lack social relationships, they do not buffer the influence of stress on learning outcomes (Lakey \& Orehek, 2011; Peplau \& Perlman, 1979). Research regarding loneliness and academic performance supports this theoretical explanation; that is, loneliness is a factor negatively influencing academic performance (Hüseyin \& Barut, 2020; Mo, 2019; Yang \& Swekwi, 2021). However, the mediating research of negative feelings, mental health, and performance revealed that the relationship of loneliness and academic performance may be an indirect, not direct, relationship (Gerino et al., 2017; Miranda et al., 2013). Good mental health is described as possessing a relaxed and healthy mental state that can positively influence both study and work (WHO, 2004). Psychological capital theory defines psychological capital as a positive psychological state produced by an individual's optimistic and resilient characteristics (Cavus \& Gokcen, 2015). The psychological state resulting from psychological capital is a mental health state (Cavus \& Gokcen, 2015; Luthans et al., 2004). Negative feelings (such as stress) can negatively affect an individual's mental health state, affecting performance (Cavus \& Gokcen, 2015; Luthans et al., 2004). Mental health has been described as a mediator not only in psychological capital theory but also in research. Studies have revealed that mental health mediates positive and negative factors (such as motivation, loneliness, and negative experiences) and outcomes (Brien et al., 2012; Gerino et al., 2017). In a study regarding the history of maternal violence, mental health, and child behavior, mental health completely mediated the negative influence of negative maternal events on child behavior (Miranda et al., 2013). In the study of loneliness, mental health, and life quality, the emotional stress of loneliness decreases an individual's life satisfaction by causing a decline in mental health (Gerino et al., 2017). Therefore, it is hypothesized that mental health is a strong mediating factor between loneliness and academic performance. In other words, loneliness can negatively affect an individual's mental health to cause a decline in academic performance. Accordingly, the hypothesis was proposed:

\section{Hypothesis: Mental health can completely mediate the influence of loneliness on the academic performance.}

A lack of social support as a stress-buffering function was inferred as the reason behind an unavoidable feeling of loneliness during independent learning (Lakey \& Orehek, 2011; Leathwood, 2006; Margalit, 1991; Peplau \& Perlman, 1979). The stress-buffering effect of social support is described as a scenario where relaxed individuals can talk to close friends and peers about private matters and ask for valid help. The process of talking about private matters, asking for problemsolving strategies, and receiving feedback are effective ways to buffer negative feelings and stress (Cohen \& Wills, 1985; Lakey \& Orehek, 2011). Thus, learners 
can ask for help from members of social support system when they face stress. However, individuals can only conduct self-comfort activities (such as enjoying food, singing songs, seeing a movie, and listening to music) to buffer negative feelings when they face stress and are lacking social support (Dahlqvist et al., 2008). Thus, a question was proposed:

Question: When the hypothetical mediating mechanism is confirmed, what kind of strategies can Chinese college students use to cope with feelings of loneliness arising from independent learning?

According to the above hypothesis and question, a hypothetical model with a complete mediation model and coping strategies was proposed as in Figure 1.

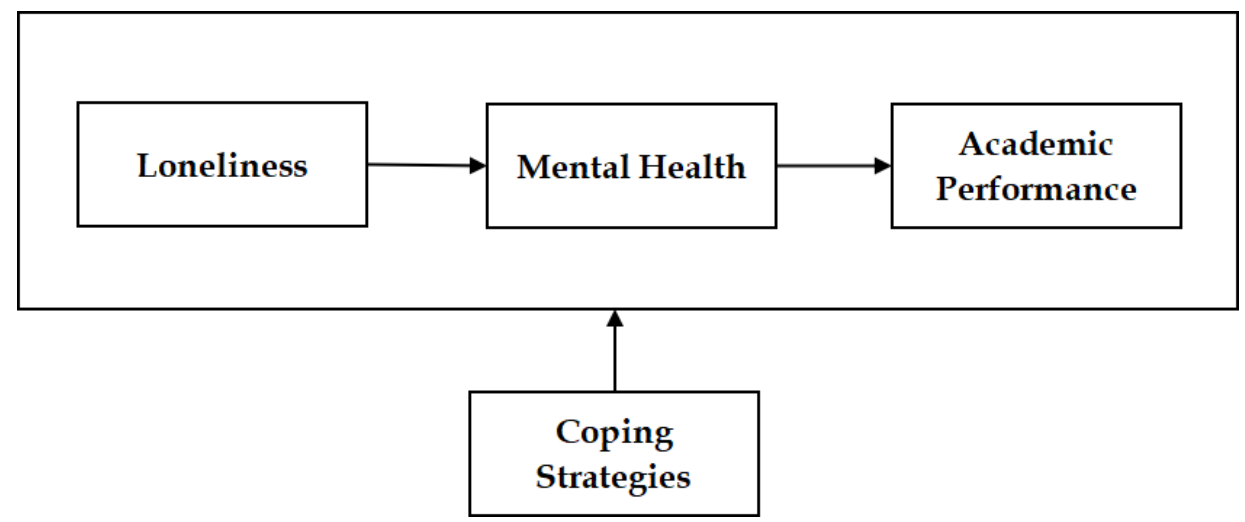

Figure 1: Hypothetical Model

\section{Structural Equation Modelling}

\subsection{Participants and research instruments}

The investigation was conducted using an online questionnaire because the COVID-19 policies in China did not permit face-to-face interviews. Table 1 shows the sample demographics, which represent the gender and grade ratio of students who participated. Purpose sampling is used to obtain samples with two features, with the sampling area experiencing the longest period of online teaching, the sampling universities containing an education and mental health center, and ever intervene online education issues, in order to ensure that samples fit the research background. University counselors assisted in recruiting participants from student dormitory groups at three universities in Wuhan city and Hubei province in China. Students from all majors were eligible for receiving the questionnaire. A total of 467 Chinese college students willingly submitted the online questionnaires by using the application WeChat. All the relevant universities had an organization facilitating the responses to issues related to student mental health or learning difficulties. Questionnaires were distributed from April 7 to April 11, 2021. A total of 30 questionnaires were extreme and were determined to be invalid. A total of 437 valid questionnaires were returned, and gender (the male-to-female ratio is close to 1:1) and grade (the proportion of students in the four grades is average) distribution ratios were in line with the group characteristics of Wuhan university students. The study protocol passed the human research ethics review of Rangsit University, Thailand, on March 5, 2021. The documentation number for the proof of 
exemption is RSUERB2021-020. The informed consent form included an explanation of the research purpose and research ethics. All college students signed the online informed consent after understanding the research purpose, voluntariness, and confidentiality.

Table 1: Demographics of Chinese college students

\begin{tabular}{|c|c|c|c|}
\hline \multirow{2}{*}{ Sex } & $\begin{array}{c}\text { Demographic } \\
\text { Characteristic }\end{array}$ & \multicolumn{2}{|c|}{$\begin{array}{c}\text { Group Number and Rate } \\
(N=437)\end{array}$} \\
\hline \multirow{3}{*}{ Grade } & Male & 208 & $47.6 \%$ \\
\cline { 2 - 4 } & Female & 229 & $52.4 \%$ \\
\cline { 2 - 4 } & Freshman & 119 & $27.2 \%$ \\
\cline { 2 - 4 } & Sophomore & 102 & $23.3 \%$ \\
\cline { 2 - 4 } & Junior & 104 & $23.8 \%$ \\
\cline { 2 - 4 } & Senior & 112 & $25.6 \%$ \\
\hline
\end{tabular}

Loneliness, mental health, and academic performance were evaluated using three measurement instruments. The effect mechanisms of these latent variables were assumed to be in accordance with theory and previous research. These three factors were measured using 5-point Likert scales ranging from 1 to 5 (strongly disagree to strongly agree), and their definitions were as follows:

(a) Loneliness, a distressing emotional stressful experience, results from a subjective feeling of dissatisfaction with social relationships (Benoit \& Ditommaso, 2020; Gerino et al., 2017; Hays \& Dimatteo, 1987). Loneliness during the independent learning process was measured by a questionnaire given to informed participants and the perceived level of loneliness during independent learning was measured using eight items on the loneliness scale. These items measured current social relationships and lonely emotional experiences (Hays \& Dimatteo, 1987; Yang \& Swekwi, 2021).

(b) Mental health is a pleasant and relaxing mental state in which individuals can focus on working and learning (WHO, 2004). The self-evaluation of mental health included an interest in life, a focus on thinking and learning, the attitude towards oneself, and stressful feelings. The degree of individual mental health was measured using six items. Forward scoring was used for five items, and one item used reverse scoring (Yao et al., 2002).

(c) Academic performance is a learning outcome indicating whether Chinese college students reached their academic potential and were prepared for future work (Yang \& Swekwi, 2021). Three academic potentials (cognitive learning, communication, and interpersonal abilities) were identified, and the Chinese college students conducted self-evaluations regarding their level of academic performance. The academic performance was assessed using 14 items; four items were for cognitive learning, five for communication, and five for interpersonal abilities (Yang \& Swekwi, 2021). 


\subsection{Measurement validity test}

The measurement items for loneliness, mental health, and academic performance passed the index of item-objective congruence (IOC) evaluation. The IOC indexes were between .80 to 1 and reflected high content validities of measurement items (Table 2). In this research, structural equation modeling (SEM) was conducted for modeling, including for confirmatory factor analysis (CFA), and for higher-order models (Byrne, 2010; Kline, 2010). Valid responses from 437 Wuhan college students were used for modeling. SPSS 21.0 was used for coding data; AMOS 21.0 was used for modeling. First, a CFA measurement model was used to verify measurement validity (Bollen, 1989; Byrne, 2010; Kline, 2010).

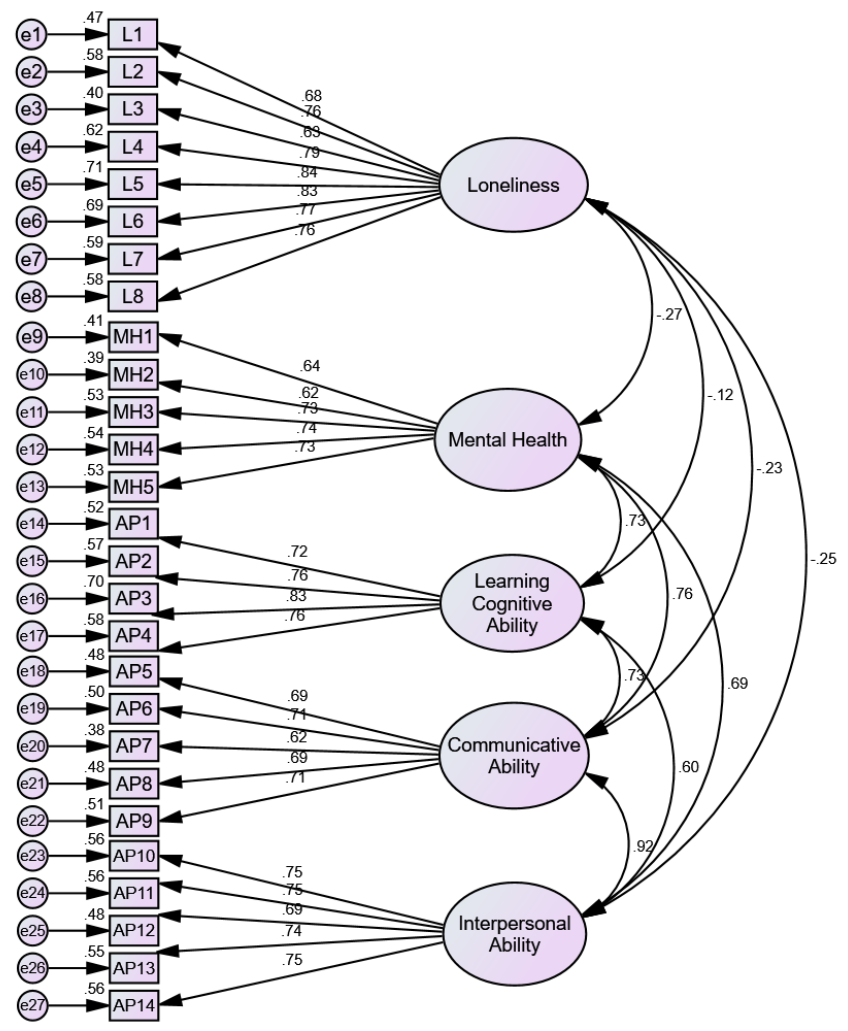

Figure 2: Measurement Model 
Table 2: Item contents, mean (M), standard deviation (SD), and standardized regression coefficients (SRC) for loneliness, mental health, and academic performance

\begin{tabular}{|c|c|c|c|c|c|}
\hline & No & Questionnaire Items & $\mathrm{M}$ & SD & SRC \\
\hline \multirow{8}{*}{ 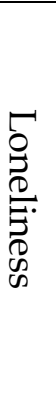 } & L1 & I lack companionship & 2.49 & 1.16 & $.68^{* * *}$ \\
\hline & $\mathrm{L} 2$ & There is no one I can turn to & 2.26 & 1.15 & $.76^{* * *}$ \\
\hline & L3 & I am a withdrawn person & 2.67 & 1.18 & $.63^{* * *}$ \\
\hline & L4 & I feel left out & 2.34 & 1.07 & $.79^{* * *}$ \\
\hline & L5 & I feel isolated from others & 2.34 & 1.12 & $.84^{* * *}$ \\
\hline & L6 & I cannot find companionship when I want it & 2.34 & 1.10 & $.83^{* * *}$ \\
\hline & L7 & I am unhappy being so withdrawn & 2.23 & 1.11 & $.77^{* * *}$ \\
\hline & L8 & People are around me but not with me & 2.39 & 1.11 & $.76^{* * *}$ \\
\hline \multirow{5}{*}{ 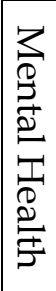 } & MH1 & I enjoy my life & 3.82 & .75 & $.64^{* * *}$ \\
\hline & MH2 & I feel that my life is meaningful & 3.90 & .82 & $.62^{* * *}$ \\
\hline & MH3 & $\begin{array}{l}\text { I can concentrate (thinking, studying, } \\
\text { remembering) on what I want to do }\end{array}$ & 3.69 & .83 & $.73^{* * *}$ \\
\hline & $\mathrm{MH} 4$ & I can accept my appearance & 3.75 & .85 & $.74^{* * *}$ \\
\hline & MH5 & I am satisfied with myself & 3.65 & .86 & $.73^{* * *}$ \\
\hline \multirow{14}{*}{$\begin{array}{l}\text { D } \\
0 \\
0 \\
0 \\
0 \\
3 \\
0 \\
0 \\
0 \\
0 \\
0 \\
0 \\
0 \\
0 \\
0 \\
0 \\
0 \\
0 \\
0\end{array}$} & AP1 & I can use the knowledge that I learned flexibly & 3.50 & .81 & $.72^{* * *}$ \\
\hline & AP2 & $\begin{array}{l}\text { I can easily understand what the teacher said } \\
\text { in class }\end{array}$ & 3.46 & .87 & $.76^{* * *}$ \\
\hline & AP3 & $\begin{array}{l}\text { I can quickly grasp the key to solving the } \\
\text { problem }\end{array}$ & 3.49 & .85 & $.83^{* * *}$ \\
\hline & $\mathrm{AP} 4$ & $\begin{array}{l}\text { I can always understand new knowledge and } \\
\text { new skills quickly }\end{array}$ & 3.51 & .85 & $.76^{* * *}$ \\
\hline & AP5 & I can communicate clearly with people & 3.69 & .84 & $.69^{* * *}$ \\
\hline & AP6 & $\begin{array}{l}\text { I know how to change the subject and can } \\
\text { master the basic talking points }\end{array}$ & 3.55 & .86 & $.71^{* * *}$ \\
\hline & AP7 & $\begin{array}{l}\text { I am good at listening and don't like to } \\
\text { interrupt others }\end{array}$ & 3.80 & .82 & $.62^{* * *}$ \\
\hline & AP8 & I can communicate with others face to face & 3.84 & .78 & $.69^{* * *}$ \\
\hline & AP9 & $\begin{array}{l}\text { I am willing to take initiative to communicate } \\
\text { with others }\end{array}$ & 3.70 & .87 & $.71^{* * *}$ \\
\hline & AP10 & $\begin{array}{l}\text { I always take initiative to help other } \\
\text { classmates }\end{array}$ & 3.69 & .86 & $.75^{* * *}$ \\
\hline & AP11 & I can take care of other classmates very well & 3.69 & .85 & $.75^{\star \star *}$ \\
\hline & AP12 & $\begin{array}{l}\text { In different situations, I can restrain my } \\
\text { behavior well }\end{array}$ & 3.89 & .80 & $.69^{* * *}$ \\
\hline & AP13 & $\begin{array}{l}\text { I can cooperate very well with other } \\
\text { classmates }\end{array}$ & 3.81 & .79 & $.74^{* * *}$ \\
\hline & AP14 & I can get along well with other people & 3.94 & .75 & $.75^{\star * *}$ \\
\hline
\end{tabular}

Next, the main effect and higher-order structural models were constructed to examine mediation effects (Bollen, 1989; Byrne, 2010; Kline, 2010). On the basis of 437 valid samples and measurement variables, a CFA measurement model was structured (Figure 2). First, the factor loadings for 27 observed variables among the 28 observed variables all exceeded .50, except for one item measuring mental health (item content: I often have negative feelings, such as worry, 
sadness, nervousness, anxiety, depression, etc.) which had a low factor loading of .22. Therefore, this item was removed from the measurement model, and 27 valid items were used (Byrne, 2010). Cronbach's a reliability coefficients for the three latent variables were $.92, .82$, and .92 .

Table 3: Model fit of the measurement model

\begin{tabular}{|c|c|}
\hline Model Fit Index & Parameter \\
\hline Chi-square $\left(\chi^{2}\right)$ & $807.77(p<.001)$ \\
\hline$\chi^{2} / \mathrm{df}$ & 2.57 \\
\hline Goodness-of-fit (GFI) & .87 \\
\hline Comparative fit index (CFI) & .92 \\
\hline Root mean square residual (RMR) & .04 \\
\hline Root mean square error of approximation (RMSEA) & .06 \\
\hline Tucker-Lewis index (TLI) & .91 \\
\hline Parsimony-adjusted NFI (PNFI) & .79 \\
\hline
\end{tabular}

Next, construct validity including convergent and discriminate validities and their indices were explained by the CFA measurement model. First, the factor loadings for 27 observed variables ranged from .62 to .84 (Figure 2); all parameters reached statistical significance and did not have negative variance (Bagozzi \& Yi, 2012). Second, the CFA measurement model had a reasonable model fit, as presented in Table 3 (Bollen, 1989; Kline, 2010). Third, the composite reliability $(\mathrm{CR})$ for loneliness, mental health, learning cognitive ability, communicative ability, and interpersonal ability in the CFA measurement model were $.92, .82, .85, .82$, and .86, respectively. The average variance extracted (AVE) of the five latent variables was .58, .48, .59, .47, and .54, respectively. The CRs all met the standard of .60, and AVEs all exceeded the standard of .40 (Hair et al., 1998). Accordingly, the measurement scales for the CFA measurement model had reasonable and convergent validities. Finally, bootstrap estimated whether the correlations were within the $95 \%$ confidence interval; the correlation estimation parameters between lower values and upper values all did not include 1 . Thus, the measurement scales had discriminant validities (Torkzadeh et al., 2003).

\subsection{Mediating result}

After CFA, a direct effect model was used to reveal the main effect relationship of loneliness on academic performance (Figure 3). Loneliness can negatively predict academic performance $(\gamma=-.23, p<.001)$, explaining $5 \%$ of the variance in academic performance. The factor loadings of all observed variables in the structural model of loneliness and academic performance were between .61 to .84. The model fit revealed that the structural model of loneliness and academic performance was acceptable: $\chi^{2}=544.74(p<.001), \chi^{2} / \mathrm{df}=2.66, \mathrm{GFI}=.90, \mathrm{RMR}$ $=.04, \mathrm{RMSEA}=.06, \mathrm{CFI}=.94, \mathrm{TLI}=.93$, and PNFI $=.80($ Kline, 2010) . 


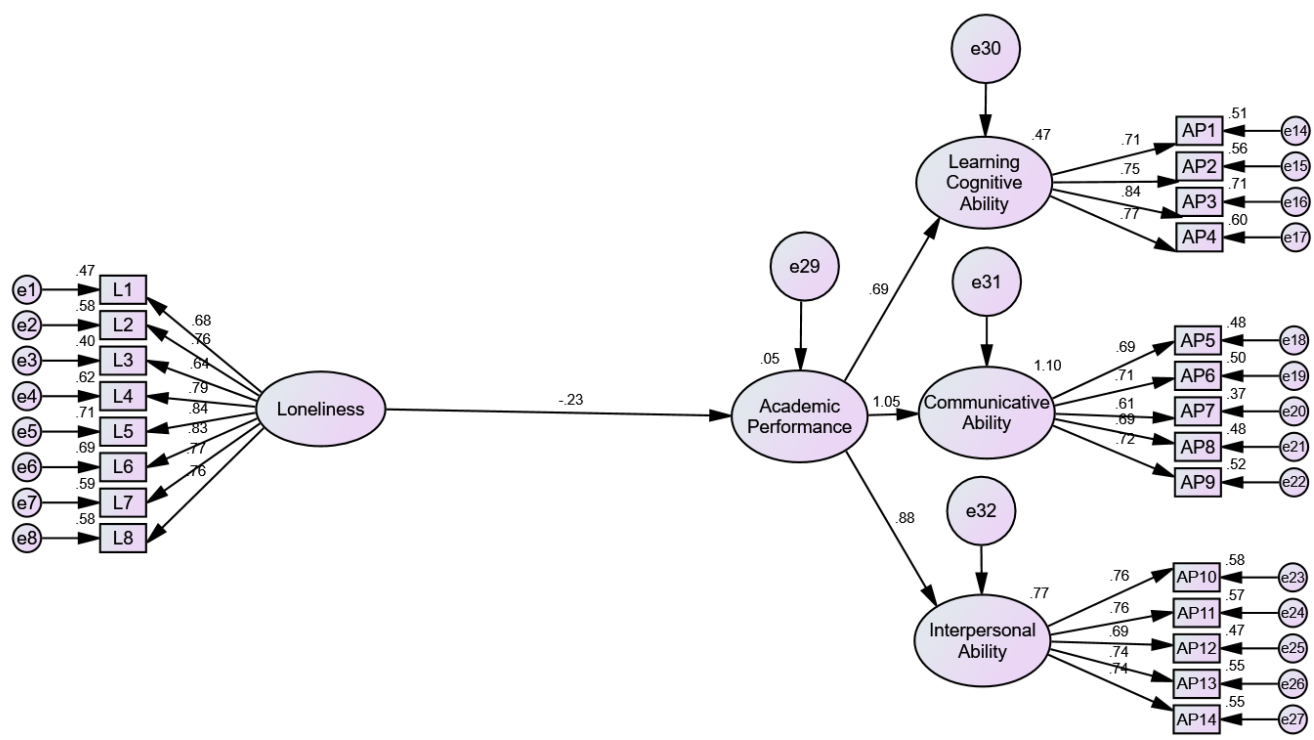

Figure 3. Structural Model of Loneliness and Academic Performance

Further, a higher-order structural model considering mental health as a mediator was constructed on the structural model of loneliness and academic performance (Figure 4). Loneliness explained $7 \%$ of the variation and was a negative predictor of mental health $(\gamma=-.27, p<.001)$. Loneliness had no negative effect on academic performance $(\gamma=-.03, p>.05)$, whereas mental health had a positive effect on academic performance $(\gamma=.78, p<.001)$. Loneliness and mental health collectively explained $63 \%$ of the variation in academic performance (Figure 4). The significance of loneliness for academic performance observed in the direct effect model disappeared in the higher-order model; the path coefficient was reduced from -.23 to -.03. The factor loadings of all items in the higher-order structural model were between .62 to .84 . The model fit revealed that the higher-order structural model was reasonable: $\chi^{2}=851.35(p$ $<.001), \chi^{2} / \mathrm{df}=2.68, \mathrm{RMR}=.04, \mathrm{RMSEA}=.06, \mathrm{GFI}=.86, \mathrm{CFI}=.92$, TLI $=.91$, and PNFI $=.79($ Kline, 2010)

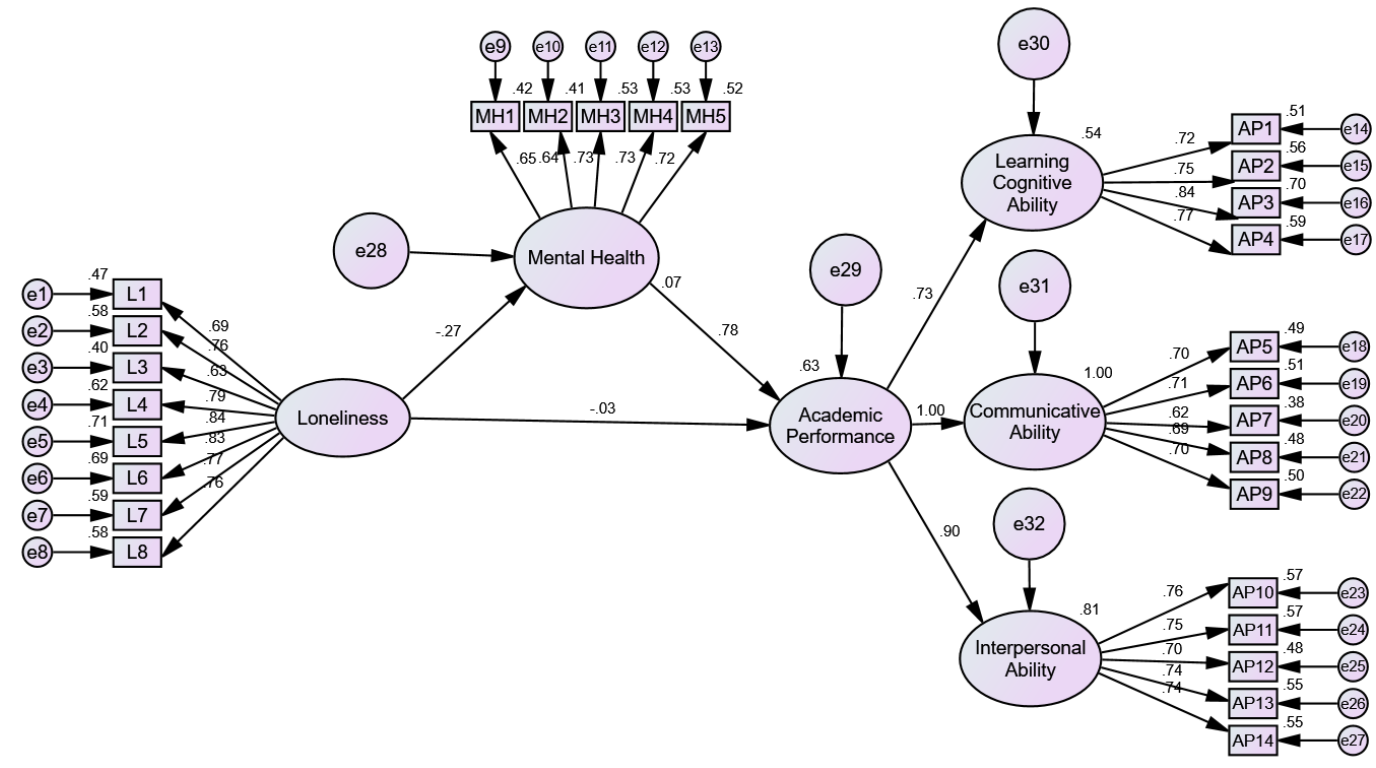

Figure 4. Higher-Order Structural Model 
Table 4. Interval estimation parameters of lower value (LV) and upper value (UV)

\begin{tabular}{|c|c|c|c|c|c|}
\hline \multirow[t]{2}{*}{ Mediating Effect } & \multirow{2}{*}{$\begin{array}{l}\text { Path } \\
\text { Value }\end{array}$} & \multicolumn{2}{|c|}{$\begin{array}{c}\text { Bias } \\
\text { Corrected }\end{array}$} & \multicolumn{2}{|c|}{ Percentile } \\
\hline & & $\mathrm{LV}$ & UV & LV & UV \\
\hline $\begin{array}{c}\text { Total effect } \\
\text { (Loneliness } \rightarrow \text { Academic Performance) }\end{array}$ & $-.13^{* * *}$ & -.20 & -.07 & -.20 & -.07 \\
\hline $\begin{array}{c}\text { Direct effect } \\
\text { (Loneliness } \rightarrow \text { Academic Performance) }\end{array}$ & -.02 & -.06 & .03 & -.06 & .03 \\
\hline $\begin{array}{c}\text { Indirect effect } \\
\text { (Loneliness } \rightarrow \text { Academic Performance) }\end{array}$ & $-.11^{* * *}$ & -.18 & -.07 & -.17 & -.06 \\
\hline
\end{tabular}

Using the bootstrap method, interval estimation in the $95 \%$ confidence interval was performed 2000 times. The results of the interval estimation revealed that the higher-order structural model was a mediating model; mental health completely mediated the main effect of loneliness on academic performance (Table 4). First, for total and indirect effects, the absence of 0 in the confidence interval estimates confirmed that the path coefficients of total effect and indirect effect were significant. However, for direct effects, confidence interval estimates for the parameters did contain 0 , indicating that direct effects were not significant. Second, the total effect of the main effect relationship reached -.13. Mental health completely mediated the main effect relationship, contributing -.11 to the indirect influence in the main effect relationship. Accordingly, the direct influence of the main effect relationship was only -.02. Therefore, mediating hypothesis of this study was confirmed.

\section{Interview}

\subsection{Interviewees and interview method}

SEM mediation results revealed that loneliness during independent learning (Leathwood, 2006; Marsh, 1997; Stoliker \& Lafreniere, 2015) causes lonely emotional stress (Gerino et al., 2017), affects individual mental health (Cavus \& Gokcen, 2015; Luthans et al., 2004) and reduces learning performance (Gerino et al., 2017; Miranda et al., 2013). To identify interventions targeting this influence mechanism, interviews with the Chinese college students were used to explore coping methods for loneliness during independent learning. Purposive sampling was used to obtain participants with a long-term independent learning experience over the duration of online teaching. A brief online interview was conducted with 12 interviewees introduced by university counselors. The interviews were all conducted with students of the most representative university of the three sampling universities, the university in which the mental health and education center led multiple intervention activities for educational issues during COVID-19. Interviews were conducted from 20 April to 28 April 2021 at the VooV Meeting. The 12 interviewees all reported similar experiences with long-term independent learning. The interview topics passed a human research ethics review from Rangsit university on 5 March 2021. The documentation number for proof of exemption is RSUERB2021-020. All 12 interviewees understood the interview topic, agreed to participate in the interview, and signed an informed consent form. The situational interview 
method was used (Latham et al., 1980). The interview situations were constructed based on the measurement concepts and SEM results, and the primary question was as follows: How can college students cope with feelings of loneliness that arise due to independent learning?

\subsection{Interview result}

The 12 interviewees (students A to L) comprised of eight females and four males have similar independent learning experiences. Their age ranges from 18 to 22 years old. The students described some methods that they use for coping with loneliness. The categories of coping strategies including self-comfort (Dahlqvist et al., 2008) and asking for help from others (Cohen \& Wills, 1985; Lakey \& Orehek, 2011), as shown in Table 5. The interview results were coded by ATLAS,ti 9. The coding in the interview results follows the "code name", "date", "gender", "grade", and "categories". For example, "Student A-20210420-M-3-2-c" reflects that Student A participated in the interview on April 20, 2021, is a male in his third year of college, and fits into coding 2 and c in Table 5.

Table 5. Interview data coding

\begin{tabular}{|l|l|l|}
\hline \multirow{4}{*}{ Coping strategies } & \multirow{2}{*}{ 1-Self-comfort } & a-Learning \\
\cline { 2 - 3 } & $\begin{array}{l}\text { 2-Asking help from } \\
\text { others }\end{array}$ & c-Friend \\
\cline { 3 - 3 } & & d-Parent \\
\cline { 2 - 3 } & e-Psychological teacher \\
\hline
\end{tabular}

Students reported coping strategies of two categories, including self-comfort (such as studying independent learning and doing relaxation) and asking help from others, such as friends, parents, or student support staff. The interview text and coding were shown as follows.

Student A explained that college students can make friends and imitate the learning techniques of others:

We can make friends and study together with friends (Student A-20210420-M-3-2-c). We can also participate in video learning online and learn how others learn independently (Student A-20210420-M-3-1-a).

Student B thought that college students who feel lonely during independent learning should make friends and maintain good relationships with them:

They can relax for a while and go hang out with a few friends (Student B-20210420-F-3-2-c). If you have a good time with your friends, you'll forget about feeling lonely. But if you don't forget, you can be friendly with people and try to talk about your loneliness (Student B-20210420-F-3-2-c). If you don't maintain a good relationship with others, others won't listen to you or care for you!

Student C suggested that students who feel lonely during the independent learning process could participate in leisure activities to relieve negative moods, and that they could search for learning partners: 
If someone has no good friends.... They could have some fun, like playing sports or reading (Student C-20210420-F-1-1-b). If they're already done studying and still feel lonely they could get out and walk around so to feel better and destress (Student C20210420-F-1-1-b). Finally, I think they should find some friends. That way, they can help each other when they have trouble understanding something in school.

Student D thought that students who feel lonely in the independent learning process could make friends with which to share their feelings, or try writing in a diary:

I think people basically social beings, so people need to make more friends. Then if you're in a bad mood you can share it with someone (Student D-20210424-F-2-2-c). If they don't have friends and can't are still in a bad mood, maybe they can get it out by writing in a diary (Student D-20210424-F-2-1-b).

Student E stated that college students who feel lonely when learning independently might not like to make friends, and suggested that they should enjoy their independence by doing something else to divert their attention from their loneliness:

I think people who feel lonely during independent learning and don't want to make friends can get along by themselves. I think students should be able to find things that interest them to divert their attention, like traveling and or playing sports (Student E20210424-F-2-1-b).

Student F suggested college students who feel lonely could get help from others or help themselves by trying to have fun:

They can get help from people around them to get out of that state.

Of course, they can also adjust on their own. If they can't stop feeling lonely, they could get help from others, and use other people's opinions to help them get through their problems. But some students might only rely on themselves. They could vent by doing something like going to exercise or by listening to music to get over negative emotions (Student F-20210424-M-2-1-b).

Student $G$ explained that college students could take the initiative to help their friends by motivating them to communicate their feelings and support them by helping them to understand that lonely feelings are normal during remote learning:

If one of my friends has emotional trouble, I'll take him out to get him to talk (Student G-20210424-M-3-2-c). Then I'll take him to our lab and show him what's going on. Our juniors are mostly working independently in the lab. Let him see that depression and loneliness are a normal thing in the independent learning process, and no one succeeds all the time. 
Student $\mathrm{H}$ suggested that parents should help college students who have a poor academic performance during independent learning to help them try to talk to other students and make more friends:

First of all, parents should pay more attention to their kids. It might take a while, but I think he might get used to talking to others and making friends (Student H-20210424-M-4-2-d). Because once he realizes that making friends is not so hard, he will try to change himself. He will look for help from his friends when he feels lonely and doesn't want to study.

Student I thought that if students feel lonely studying alone, they could find friends and study together:

I think I can prepare for class together with my classmates (Student I-20210427-F-4-2-c). When we prepare for class together, I feel that someone is studying with me, so I don't feel so lonely - I feel like we're making progress together.

Student J suggested the students who feel lonely could participate in something enjoyable or try to make friends with common interests:

People should have their own way of relaxing. Do what they like, sing a song, listen to a song, or do something else (Student J20210427-F-1-1-b). I also think they could make friends with common interests (Student J-20210427-F-1-2-c).

Student K said that students who feel lonely should first settle themselves and then express their emotions by communicating:

They just need to calm down and find a direction. They could chat with some like-minded friends online. They could also post something (like their feelings and recent stories) on social media, and then someone might come comfort them (Student K-20210427-F-1-2-c).

Student L suggested that students could ask for help from psychology teachers: We all have specialized psychology teachers in our college. I think if students aren't willing to talk to their parents or friends, they could talk with the psychology professor, and the psychology teacher might help them (Student K-20210428-F-3-2-e). 


\section{Discussion}

The hypothesis of this study was verified by SEM. The result of the main effect relationship of loneliness on academic performance aligned with previous research regarding loneliness and academic performance (Hüseyin \& Barut, 2020; Mo, 2019; Yang \& Swekwi, 2021). On the basis of the social-psychological theory of loneliness and stress-regulation theory (Lakey \& Orehek, 2011; Peplau \& Perlman, 1979), the predicted direct effect is that the influence of loneliness on learning outcomes is down to emotional stress. Emotional stress occurs when lonely individuals lack companionship and social support (Kaufmann \& Vallade, 2020; Leathwood, 2006; Marsh, 1997). Therefore, these individuals do not have access to the stress-buffering function of social relationships and feel lonely during the independent learning process, affecting learning outcomes (Lakey \& Orehek, 2011; Peplau \& Perlman, 1979). However, the SEM mediating result revealed the relationship between loneliness and academic performance was an indirect relationship because mental health can completely mediate the influence of loneliness on the academic performance of Chinese college students. Loneliness can negatively affect mental health to in turn impact academic performance. The confirmation of the mediating role of mental health on loneliness and academic performance differs from previous research on loneliness and academic performance (Hüseyin \& Barut, 2020; Mo, 2019; Yang \& Swekwi, 2021), but agrees with the mediating research on mental health (Brien et al., 2012; Gerino et al., 2017; Miranda et al., 2013). According to the socialpsychological theory of loneliness, social support stress-regulation theory, and psychological capital theory (Cavus \& Gokcen, 2015; Luthans et al., 2004; Lakey \& Orehek, 2011; Peplau \& Perlman, 1979), the mechanism of loneliness, mental health, and academic performance for independent learners may be explained as the fact that independent learning is a learning style that takes learners into a state of loneliness, without social support (Kaufmann \& Vallade, 2020; Leathwood, 2006; Marsh, 1997). The emotional stress arising from loneliness (Gerino et al., 2017) cannot be buffered by the social support system (Lakey \& Orehek, 2011; Peplau \& Perlman, 1979). Accordingly, emotional stress arising from loneliness can negatively affect individual mental health and reduce individual achievement in academics (Cavus \& Gokcen, 2015; Luthans et al., 2004).

Based on the above SEM results and theoretical explanation, independent learners who are affected by the mechanism of loneliness, mental health, and academic performance may have learning burnout or experience complete cessation of independent learning (Leathwood, 2006; Marsh, 1997). To identify an intervention for the mechanism of this negative influence and to answer the question of this study, interviews were conducted. In the interview text, all twelve students reported that self-comfort and asking help from others could reduce the effects of loneliness. The coding data combined with interview text was used to propose two suggestions to buffer loneliness arising from independent learning.

The first suggestion from students was self-comfort, which is suitable for those without social support (Dahlqvist et al., 2008). College students should have their own methods for learning and relaxation during independent learning. For 
example, online resources (such as videos) explaining independent learning methods could help them understand how to learn independently and effectively. Other strategies for mood improvement mentioned by the students were traveling, writing in a diary, listening to music, singing songs, reading books, and exercising.

The second suggestion was to ask for help from others (such as friends, parents, and psychological teachers), and this is suitable for students who are willing to obtain help from the interpersonal support (Cohen \& Wills, 1985; Lakey \& Orehek, 2011). Firstly, students can make friends to study and talk with to manage negative emotions. Friends can be learning partners; one response typical of student reasoning was "When we prepare for class together, I feel that someone is studying with me, so I don't feel so lonely - I feel like we're making progress together." Emotions can be shared with friends. Assistance from friends could inspire these students to communicate more and to help them understand that lonely feelings are normal during independent learning. Expressing negative emotions on social media could facilitate receiving comfort from net friends. The rationale of making friends for emotional support was reported by one student as, "I think that people are basically social beings, so people need to make more friends. Then if you're in a bad mood, you can share it with someone." Further, the student added that having fun with friends can alleviate loneliness. Notably, discussing negative feelings with friends requires a good relationship with close friends who care about one's problems. Secondly, soliciting perspectives from others could help struggling students overcome their problems. Parents could help students learn how to communicate with others and to make friends. Finally, speaking with psychology teachers at college could also be helpful for learning strategies to ease loneliness.

\section{Conclusion}

Mental health was revealed to completely mediate the influence of loneliness on academic performance. Loneliness is commonly experienced by students during independent learning and is a key factor negatively influencing academic performance, but mental health is a mediator between loneliness and academic performance. Students perceive that loneliness during independent learning can negatively affect mental health to decrease academic performance. To mitigate the negative influence of feelings of loneliness on mental health and to protect learning outcomes, students suggested that lonely independent learners lacking social support could use self-comfort strategies to cope with independent learning methods and distract themselves and relax after learning. The lonely independent learners who do have social support can ask to study with friends or ask for help from friends, parents, and psychological teachers to ease the lonely emotional stress.

\section{Research Suggestions}

The results indicate that to help Chinese college students adapt to online education, Chinese universities should help the students overcome obstacles for independent learning in accordance with the mechanisms revealed in this study. 
First, online teaching has become unavoidable during the era of COVID-19 (Mishra et al., 2020; Mahmood, 2021). Additionally, independent learning is essential for successful online teaching in Chinese higher education (Zhang et al., 2020). However, the negative influence of loneliness on mental health and academic achievement indicated that loneliness is harmful for independent learning and is a key reason that Chinese college students struggled when learning independently (Kaufmann \& Vallade, 2020; Marsh, 1997). Therefore, we suggest that people involved in Chinese higher education should consider loneliness as a factor influencing the academic performance of Chinese college students during the pandemic, and they should assist them in adapting to independent learning, thereby becoming effective independent learners and adapting to future online education and work.

Second, previous research, theory, and SEM results jointly revealed the negative effects and relationships of loneliness during independent learning, mental health, and academic performance. On the basis of the interviews conducted in this research, several methods for coping with loneliness due to independent learning were identified. Hence, we recommend that college counselors managing learning issues and mental health in Chinese higher education settings should consider assisting college students to learn coping methods for loneliness. For example, students should attempt to develop self-comfort strategies and ask for help from friends, parents, and psychological teachers when they feel loneliness and emotional pressure due to independent learning.

\section{Limitations and Future Research}

In this research, only the relationships between loneliness, mental health, and academic performance were explored using SEM. A complete mediating relationship was identified. Therefore, the subsequent SEM-based research should explore additional factors, such as social support, which could obstruct this mechanism.

Mixed method research was conducted using both investigations and interviews. However, research combining SEM and interviews is unusual. SEM was used to explore influence mechanisms, whereas interviews were used to explore methods for coping with the influence mechanisms (i.e., loneliness). Subsequent research including both SEM analysis and interviews should refer to the methods used in this study.

\section{References}

Aristovnik, A., Keržič, D., Ravšelj, D., Tomaževič, N., \& Umek, L. (2020). Impacts of the COVID-19 pandemic on life of higher education students: A global perspective. Sustainability, 12(20), 8438. https:// doi.org/10.3390/su12208438

Bagozzi, R. P., \& Yi, Y. (2012). Specification, evaluation, and interpretation of structural equation models. Journal of the Academy of Marketing Science, 40(1), 8-34. https:// doi.org/10.1007/s11747-011-0278-x

Bollen, K.A. (1989). Structural equations with latent variables. Wiley.

Byrne, B. B. (2010). Structural equation modeling using AMOS: Basic concepts, applications, and programming (2nd ed.). Taylor \& Francis Group. 
Benoit, A., \& DiTommaso, E. (2020). Attachment, loneliness, and online perceived social $\begin{array}{lllll}\text { support. Personality and Individual Differences, } & 167 .\end{array}$ https://doi.org/10.1016/j.paid.2020.110230

Brien, M., Hass, C., \& Savoie, A. (2012). Psychological health as a mediator between need satisfaction at work and teachers' self-perceptions of performance. Canadian Journal of Behavioural Science, 44(4), 288-299. https://doi.org/10.1037/a0028056

Cavus, M. F., \& Gokcen, A. (2015). Psychological capital: Definition, components and effects. Journal of Education, Society and Behavioural Science, 244-255. https://doi.org/10.9734/BJESBS/2015/12574

Cohen, S., \& Wills, T. A. (1985). Stress, social support, and the buffering hypothesis. Psychological Bulletin, 98(2), 310-357. https://doi.org/10.1037/0033-2909.98.2.310

Diehl, K., Jansen, C., Ishchanova, K., \& Hilger-Kolb, J. (2018). Loneliness at universities: Determinants of emotional and social loneliness among students. International Journal of Environmental Research and Public Health, 15(9), 1865. https:// doi.org/10.3390/ijerph15091865

Dahlqvist, V., Söderberg, A., \& Norberg, A. (2008). Dealing with stress: Patterns of selfcomfort among healthcare students. Nurse Education Today, 28(4), 476-484 https://doi.org/ 10.1016/j.nedt.2007.07.010

Gerino, E., Rollè, L., Sechi, C., \& Brustia, P. (2017). Loneliness, resilience, mental health, and quality of life in old age: A structural equation model. Frontiers in Psychology, 8, 2003. https://doi.org/10.3389/fpsyg.2017.02003

Hair, J. F. Jr., Anderson, R. E., Tatham, R. L., \& Black, W. C. (1998). Multivariate data analysis (5th ed.). Prentice-Hall.

Hays, R. D., \& DiMatteo, M. R. (1987). A short-form measure of loneliness. Journal of Personality Assessment, 51(1), 69-81. https://doi.org/10.1207/s15327752jpa5101_6

Hüseyin, E. R. İ. Ş., \& Barut, S. (2020). The Effect of feeling of loneliness on burnout levels in university students. Journal of Theoretical Educational Science, 13(2), 369383. https:// doi.org/10.30831/akukeg.606671

Kline, R. B. (2010). Principles and practice of structural equation modeling (3rd ed.). Guilford.

Kaufmann, R., \& Vallade, J. I. (2020). Exploring connections in the online learning environment: Student perceptions of rapport, climate, and loneliness. Interactive Learning Environments, 1-15. https:/ / doi.org/10.1080/10494820.2020.1749670

Luthans, F., Luthans, K. W., \& Luthans, B. C. (2004). Positive psychological capital: Beyond human and social capital. Business Horizons, 47(1), 45-50. https://doi.org/10.1016/j.bushor.2003.11.007

Leathwood, C. (2006). Gender, equity and the discourse of the independent learner in higher education. Higher education, 52(4), 611-633. https:// doi.org/10.1007/s10734-005-2414-3

Latham, G. P., Saari, L. M., Pursell, E. D., \& Campion, M. A. (1980). The situational interview. Journal of Applied Psychology, 65(4), 422-427. https://doi.org/10.1037/0021-9010.65.4.422

Lakey, B., \& Orehek, E. (2011). Relational regulation theory: A new approach to explain the link between perceived social support and mental health. Psychological Review, 118(3), 482-495. https://doi.org/10.1037/a0023477

Marsh, D. (1997). Computer conferencing: Taking the loneliness out of independent learning. Language Learning Journal, 15(1), 21-25. https://doi.org/10.1080/09571739785200051

Margalit, M. (1991). Understanding loneliness among students with learning disabilities. Behavior Change, 8(4), 167-173. https://doi.org/10.1017/S0813483900006641

Mahmood, S. (2021). Instructional strategies for online teaching in COVID-19 pandemic. Human Behavior and Emerging Technologies, 3(1), 199-203. https://doi.org/10.1002/hbe2.218 
Miranda, J. K., de la Osa, N., Granero, R., \& Ezpeleta, L. (2013). Maternal childhood abuse, intimate partner violence, and child psychopathology: The mediator role of mothers' mental health. Violence Against Women, 19(1), 50-68. https://doi.org/10.1177/1077801212475337

Mo, T. S. (2019). The interrelationship of loneliness, social desirability and academic achievement in Myanmar adolescents: Viewing social desirability from adjustment approach. European Journal of Education Studies, 5(11), 187-197. http://doi.org/ 10.5281/zenodo.2588263

Mishra, L., Gupta, T., \& Shree, A. (2020). Online teaching-learning in higher education during lockdown period of COVID-19 pandemic. International Journal of Educational Research Open, 1, 100012. https://doi.org/10.1016/j.ijedro.2020.100012

Peplau, L. A., \& Perlman, D. (1979). Blueprint for a social psychological theory of loneliness (pp. 101-110). Pergamon Press.

Stoliker, B. E., \& Lafreniere, K. D. (2015). The influence of perceived stress, loneliness, and learning burnout on university students' educational experience. College Student Journal, 49(1), 146-160. https://www.ingentaconnect.com/content/prin/csj/2015/00000049/00000001 /art00015

Torkzadeh, G., Koufteros, X., \& Pflughoeft, K. (2003). Confirmatory analysis of computer self-efficacy. Structural Equation Modeling: A Multidisciplinary Journal, 10(2), 263 275. https://doi.org/10.1207/S15328007SEM1002_6

WHO. (2020). Healthy at home. https://www.who.int/campaigns/connecting-the-worldto-combat-coronavirus/healthyathome/healthyathome---mental-health

WHO. (2004). Promoting mental health: Concepts, emerging evidence, practice (Summary Report).

https://www.who.int/mental_health/evidence/en/promoting_mhh.pdf

Wang, C., Cheng, Z., Yue, X. G., \& McAleer, M. (2020). Risk management of COVID-19 by universities in China. Risk and Financial Management, 13, 36. https:// doi.org/10.3390/jrfm13020036

Yu, L., Huang, L., Tang, H. R., Hu, D., Feng, W. Y., \& Shi, L. X. (2020). Analysis of factors influencing the network teaching effect of college students in a medical school during the COVID-19 epidemic. BMC Medical Education. https://doi.org/10.21203/rs.3.rs-51827/v1

Yang, D., \& Swekwi, U. (2021). The mediating effect of resilience on the relationship between loneliness and academic performance in Wuhan's college students. Asian Journal of Management Sciences \& Education, 10(1), 96-107. http://www.ajmse.leena-luna.co.jp/AJMSEPDFs/Vol.10(1)/AJMSE2021(10.110).pdf

Yao, G., Chung, C. W., Yu, C. F., \& Wang, J. D. (2002). Development and verification of validity and reliability of the WHOQOL-BREF Taiwan version. Journal of the Formosan Medical Association, 101(5), 342-351. https:// citeseerx.ist.psu.edu/viewdoc/download?doi=10.1.1.466.3701\&rep=rep $1 \&$ type $=$ pdf

Zhang, W., Wang, Y., Yang, L., \& Wang, C. (2020). Suspending classes without stopping learning: China's education emergency management policy in the COVID-19 outbreak. Journal of Risk and Financial Management, 13(3), 55. https://doi.org/10.3390/jrfm13030055 